\title{
FLEX FATIGUE BEHAVIOR OF PLASTIC OPTICAL FIBERS WITH LOW BENDING CYCLES
}

\author{
Juan Huang, Dana Křemenáková, Jiří Militký \\ Technical University of Liberec, Faculty of Textile Engineering, Department of Material Engineering \\ Studentská 1402/2, 46117 Liberec 1 \\ Tel: (+420) 485353471 \\ E-mail: juan.huang@tul.cz, dana.kremenakova@tul.cz, jiri. militky@tul.cz
}

\begin{abstract}
:
Flex fatigue behaviour of plastic optical fibres (POFs) with the diameters of 0.2 and $0.3 \mathrm{~mm}$ under different pretensions is measured with fatigue life curve by flexometer. The fatigue sensitivity coefficient is calculated by the linear fitting curve of normalised stress versus logarithm of bending cycles. The residual modulus is investigated during the flex fatigue processes. The results exhibit the exponential relationship between applied pretension and numbers of bending cycles at break. It is indicated that the flex fatigue of POFs might be sensitive with high swing angle or swing speed. There is an evident loss of modulus for two POFs with pretensions of 4 and $10 \%$ of ultimate tensile strength during 10-times bending cycles. The values of residual modulus of two POFs almost keep constant after 10-times bending cycles.
\end{abstract}

\section{Keywords:}

Flex fatigue, plastic optical fibres, bending cycles, pretension, residual modulus

\section{Introduction}

Flex fatigue is significant for plastic optical fibres (POFs) applied in textile structures as warps or wefts due to the limitation of flexibility of POFs. When a POF is bent, both stretch and compress occur simultaneously in the opposite sides, which not only influences the pulse delay or phase shift, leading to the changes of transmission of optical signals, but also plays a big role in mechanical properties.

Fatigue behaviour is the tendency of a material to destruct under cyclic stresses. Fatigue strength, which is expressed by the number of cycles at break under repeated stresses, indicates the ability of the sample to endure to the moment of failure and decreases with the increase of applied stress. Researchers have made great efforts to study the fatigue behaviour of optical fibres. Matthewson has studied static fatigue, the environmental effects on static fatigue, the fatigue crack growth model and the dynamic fatigue in two-point bending of optical fibres [1-4]. With the development of optical fibre technology, fatigue resistance of optical fibre has been investigated [5]. The differences of fatigue behaviour measured by tensile and bending tests have been discussed [6]. Meanwhile, the fatigue behaviour of optical fibres with defects has been studied [7]. The fatigue life curve for POFs has not been discussed in detail.

Generally, the fatigue behaviour is measured by strength testing equipment designed for fatigue tests [8]. Flexometer, which is normally used to study the flex fatigue resistance of fibres and simple composites, is employed to measure the flex fatigue life curves of POFs in the present study. The stress is related to the ultimate tensile strength of POFs calculated from the tensile testing. The main aim of this study is to evaluate the flex fatigue behaviour of POFs with different diameters and analyse the fatigue sensitivities and residual modulus.

\section{Experimental}

\section{Materials}

Table 1 exhibits the basic description about POFs purchased from HYPOF Fiber Optic Lighting, Inc., Houston, Texas, United States.

Table 1. Basic properties of HYPOF POFs.

\begin{tabular}{|c|c|}
\hline Basic properties & Values \\
\hline Core material & PMMA \\
\hline Diameter & $0.2 / 0.3 \mathrm{~mm}$ \\
\hline Core refraction index & 1.492 \\
\hline Cladding refraction index & 1.402 \\
\hline Numerical aperture & 0.51 \\
\hline Temperature range & $-55 \sim+70^{\circ} \mathrm{C}$ \\
\hline Maximum attenuation & $0.2 \mathrm{~dB} / \mathrm{m}$ \\
\hline Limit of bending radius & $8 \times$ fibre diameter \\
\hline
\end{tabular}

\section{Tensile testing}

The tensile testing was performed to investigate the fundamental mechanical characterisations by Instron- 4411 tester at $20^{\circ} \mathrm{C}$ room temperature and $65 \%$ relative humidity. The gauge between two holders was $200 \mathrm{~mm}$ and the testing speed was $100 \mathrm{~mm} / \mathrm{min}$. 50 times were averaged for each type of POFs. 


\section{Flex fatigue testing}

Classical fatigue testes are based on the constant amplitude experiments, as shown in Figure 1. Stress cycle is characterised by stress range $\Delta \sigma$ that equals the difference between the maximum stress $\sigma_{\max }$ and the minimum stress $\sigma_{\text {min }}$.

The stress ration $R$, the mean stress level $\sigma_{m}$ and the stress amplitude can be expressed by:

$$
\begin{gathered}
R=\sigma_{\text {min }} / \sigma_{\text {max }} \\
\sigma_{\mathrm{m}}=\left(\sigma_{\text {min }}+\sigma_{\text {max }}\right) / 2 \\
\sigma_{a}=\left(\sigma_{\text {max }}-\sigma_{\text {min }}\right) / 2=\Delta \sigma / 2
\end{gathered}
$$

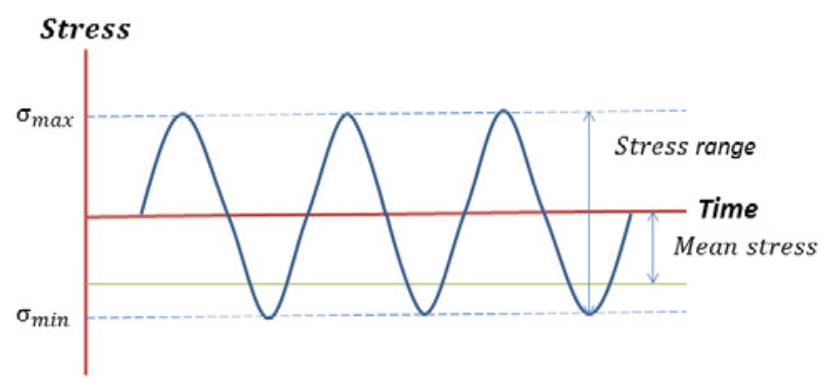

Figure 1. Cyclic variation of stress in fatigue test.

The stress life method is one of the classical fatigue methods; the basis of this method is the $S-N$ curve (Wöhler curve), which is dependence of $\sigma_{a}$ (for $\sigma_{m}=0$ ) or $\left(\sigma_{a}+\sigma_{m}\right)$ on the number of cycles $N$ to failure. The fatigue test may be carried out using one kind of load (such as compressing, bending, twisting or torque) or different kinds of loads during one cycle. Three significant tensions, therefore, are distinguished [8]. One-side tension means $\sigma_{\max }$ has the same sign as $\sigma_{\min }$. Two-side tension indicates $\sigma$ max has different value as well as different sign from $\sigma_{\min }$. While in the case of pulsing tension or zero suppressed tension, $\sigma_{\max }$ has different sign but same absolute value from $\sigma_{\min }$, that is, the mean stress level $\sigma_{m}=0, R=-1$.

The flex fatigue testing was carried out with the flexometer (Figure 2 ) at $20^{\circ} \mathrm{C}$ room temperature and $65 \%$ relative humidity in order to evaluate the number of bending cycles required for the failure of POFs. This testing is with zero suppressed tension, which means the stress level is zero, the maximum stress exhibits the different sign and the same value as the minimum stress. POFs with $300 \mathrm{~mm}$ length were clamped to the upper jaw that provided an adjustable pre-swing radius for measurements, and inserted into the law jaw that makes fibres move in the vertical direction rather than horizontal direction. The swing angle in this study was designed in the range of $20-160^{\circ}$, and the drive motor connected to the upper jaw was set as 100 , which was related to the swing speed of 116 times per minute. Figure 2 shows the fibre under both straight state (solid lines) and bending state (dash lines). The movement of fibre is repeatable and starts from the middle place to the right side first, then to the left side, then to the right side, and stops when fibre failure happens. When fibre is in the left part, left bending occurs; when fibre is in the right part, right bending occurs. The fibre is only bent during the bending zone that is 8 $\mathrm{cm}$ shown in fig. 2, from the edge of the upper jaw to the edge of the lower jaw. The weight $(m)$ could be applied to the free end of POFs. Fifty times were averaged for each type of fibres.

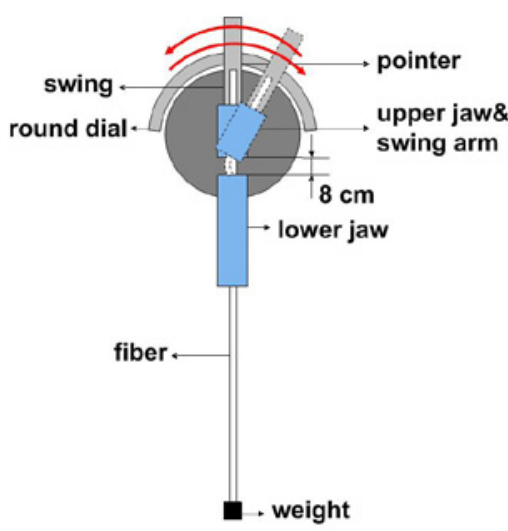

Figure 2. Schematic diagram of the device to measure bending resistance of samples.

\section{Results and Discussions}

\section{Tensile properties of POFs}

Compared with POF of $0.3 \mathrm{~mm}$ diameter, POF of $0.2 \mathrm{~mm}$ diameter shows higher strength (MPa), greater Young's modulus and smaller strain, as shown in Table 2 and Figure 3. It is indicated that the fine POF is relatively stiff and obviously flexible, with the value 3.75 times higher than that of coarse POF.

\begin{tabular}{|c|c|c|c|c|}
\hline $\begin{array}{l}\text { Diameter } \\
\text { [mm] }\end{array}$ & $\begin{array}{c}\text { Strain } \\
{[\%]}\end{array}$ & $\begin{array}{c}\text { Tensile } \\
\text { strength } \\
\text { [MPa] }\end{array}$ & $\begin{array}{c}\text { Young's } \\
\text { modulus } \\
\text { [GPa] }\end{array}$ & $\begin{array}{l}\text { Flexibility } \\
{\left[\mathrm{N}^{-1} \mathbf{m m}^{-2}\right]}\end{array}$ \\
\hline 0.2 & $\begin{array}{r}19.93 \\
(19.92, \\
21.94)\end{array}$ & $\begin{array}{c}99.05 \\
(95.89 \\
102.20)\end{array}$ & $\begin{array}{c}3.57 \\
(3.47 \\
3.67)\end{array}$ & $\begin{array}{c}3.60(3.50 \\
3.70)\end{array}$ \\
\hline 0.3 & $\begin{array}{l}48.35 \\
(44.08, \\
52.62)\end{array}$ & $\begin{array}{c}70.90 \\
(68.93 \\
72.87)\end{array}$ & $\begin{array}{l}2.65 \\
(2.58 \\
2.72)\end{array}$ & $\begin{array}{c}0.96(0.93 \\
0.98)\end{array}$ \\
\hline
\end{tabular}

Table 2. Values and corresponding $95 \%$ confidence interval for basic mechanical properties of POFs.

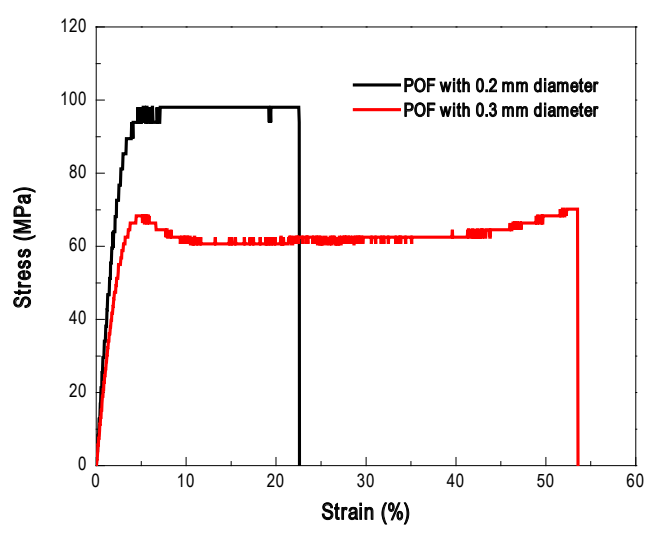

Figure 3. Typical curves of stress versus strain of POFs. 


\section{Flex fatigue behaviour of POFs}

Flex fatigue life

The pretension $(\sigma)$ given by the force from the weight $(m)$ is calculated based on ultimate tensile strength $\sigma_{u t s}$

$$
\sigma /\left(\pi r^{2}\right)=m g /\left(\pi r^{2}\right)=\alpha \cdot \sigma_{u t s}
$$

where $g$ is the earth acceleration, $\alpha_{c}$ is the ratio of elaborated fatigue strength to ultimate tensile strength based on the experience. Normally, the value of $\alpha_{c}$ is in the range of $50-98 \%$ for tensile tests and bending technique. While it was found from the flex fatigue life curve in Figure 4 that the value of $\sigma_{c}$ is visibly boarder. This phenomenon might be attributed to the greater bending angle or speed for POFs in this experiment, which would result in a relatively narrower transition zone less than $20 \%$ for each curve. Below the transition zone, two kinds of POFs present high fatigue resistance to the small temporary stress, which shows an opposite tendency above this transition zone.

Compared with the POF of $0.3 \mathrm{~mm}$ diameter, it is interesting to note that POF of $0.2 \mathrm{~mm}$ diameter exhibits higher bending cycles at break under the pretension less than approximately $38 \%$ of ultimate tensile strength, and lower bending cycles at break under the pretension more than this value. That means, the fine POF has a high fatigue resistance to the small temporary stress and low fatigue resistance to the high temporary stress. The images of scanning electron microscopy (SEM) in Figure 5 show the morphologies of bending fracture of POFs. There is obvious plastic deformation for two fibres. The sections are uneven and sloping down from the stretched side to the compressed side. The sloping section is evident for POF of $0.3 \mathrm{~mm}$ diameter, which might be related to the high strain.

The results show the typical exponential relationship between pretension and bending cycles, and the empirical equations of flex fatigue life are shown as follows,

$$
\begin{aligned}
& y=52.24 \times \exp (-x / 5.99)+63.63 \times \exp (-x / 676.37)+1.18 \\
& y=43.44 \times \exp (-x / 441.98)+43.44 \times \exp (-x / 442.00)+1.28
\end{aligned}
$$

\section{Fatigue sensitivity coefficient}

The fatigue sensitivity coefficient can be calculated according to the normalised S-N curve,

$$
\sigma_{a} / \sigma_{u t s}=1-b \cdot \log N
$$

where $\sigma a$ is the applied peak pretension, the constant $b$ related to the slope of the normalised $S-N$ curve is fatigue sensitivity coefficient. The value of $b$ is remarkably close to 0.1 for chopped E-glass strand composites [9]. The experimental results in this work is markedly different, $b$ is equal to 0.27 and 0.26 for POFs with 0.2 and $0.3 \mathrm{~mm}$ diameters, respectively, as shown in Figure 6 . It could be explained by the high swing angle or swing speed. The bending cycles is greater with smaller swing angle or speed. The flex fatigue of POFs would be more sensitive with great bending angle or speed. The structure and fracture mechanism of fibre composites, which are different from those of single optical fibre also influence the experimental results.

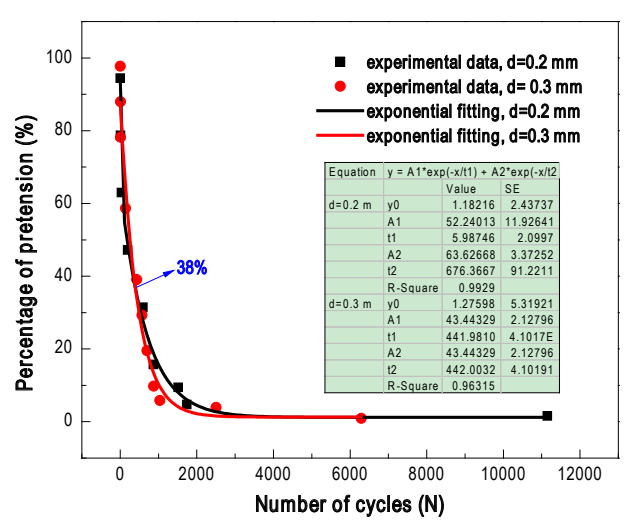

Figure 4. $S-N$ curve for plastic optical fibres.

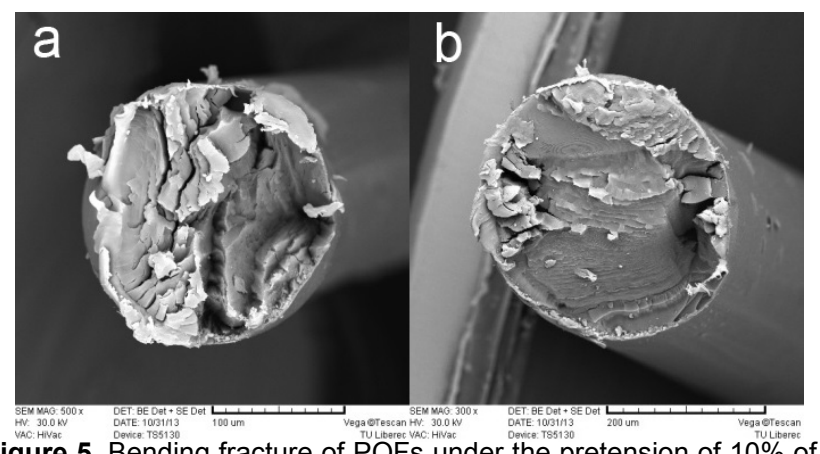

Figure 5. Bending fracture of POFs under the pretension of $10 \%$ of ultimate tensile strength: (a) $0.2 \mathrm{~mm}$ diameter; (b) $0.3 \mathrm{~mm}$ diameter.

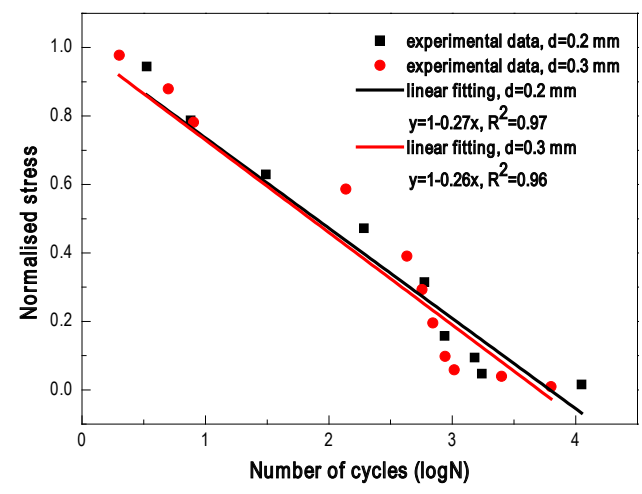

Figure 6. Normalised $S-N$ curve for plastic optical fibres.

\section{Residual modulus}

Some specimens were taken out from the device during the flex fatigue experiments in order to investigate the residual modulus. It is visible from the values of residual modulus for both kinds of POFs that, these is no significant modulus degradation with the increase in bending cycles when the pretension is below the transition zone less than $20 \%$ of ultimate tensile strength (Figure 7). The residual modulus is calculated as less than $3 \%$ of the original modulus for each fibre (Figure 8), which means 
there is an evident loss of modulus of POFs during 10-times bending cycles.

This phenomenon is quite distinct from that of hemp fibre or glass fibre reinforced composites [10]. The bending condition (bending angle or bending speed rather than bending cycles) might have an amazing influence on the modulus, or the limited bending radius might have a greater impact than bending cycles in present work. The bending angle and speed should be seriously considered and studied further.

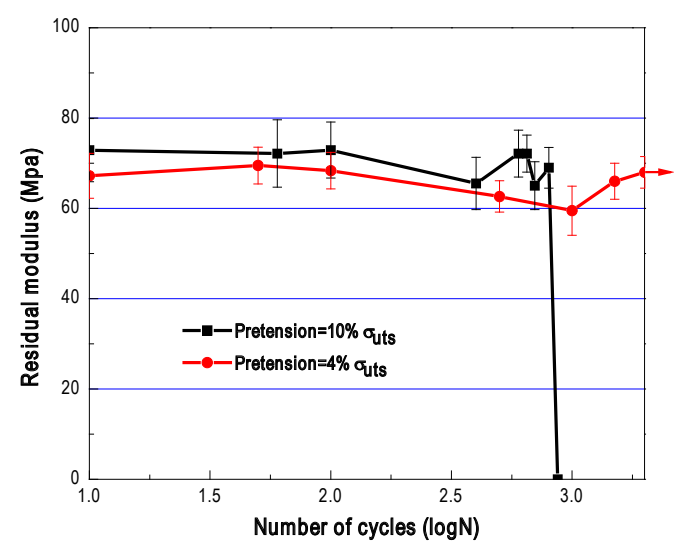

Figure 7. Residual modulus for POFs of $0.3 \mathrm{~mm}$ diameter.

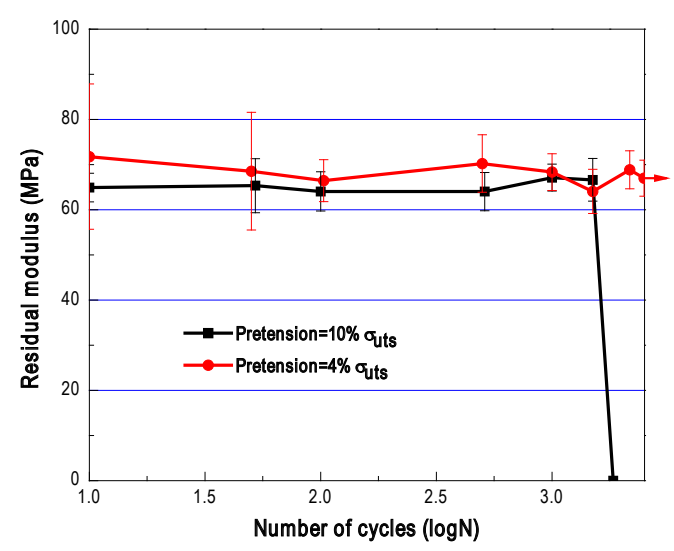

Figure 8. Residual modulus for POFs of $0.2 \mathrm{~mm}$ diameter.

\section{Conclusions}

Flex fatigue life curve illustrates the exponential dependence between pretension and flex fatigue characteristics, expressed by the percentage of ultimate tensile strength of POF and corresponding numbers of bending cycles at break with flexometer. The flex fatigue resistance to pretension is increased with decreasing pretension. The fine POF with higher tensile strength and flexibility presents better flex fatigue resistance under smaller pretension than coarse POF. The fatigue sensitivity coefficient is obvious higher than the value (0.1) of fibre-based composites due to the extensive swing angle or speed for POFs with limited bending radius or special structure. The values of residual modulus indicate that the bending cycles play little role in the residual modulus when the pretension is below the transition zone of less than $20 \%$ of ultimate tensile strength.

It is interesting to study the flex fatigue life with smaller swing angle or speed in the future as POFs produced for efficient data transmission have the limitation of flexibility. High bending angle or speed could lead to easy destruction of POFs due to the limited resistance to flex fatigue.

\section{Acknowledegment}

This work was supported under SGS project by Technical University of Liberec.

\section{References}

[1] M.J. Matthewson, C.R. Kurkjian: Static fatigue of optical fibers in bending, Journal of the American Ceramic, 1987, vol. 70, no. 9, p. 662-668.

[2] M.J. Matthewson, C.R. Kurkjian: Environmental Effects on the Static Fatigue of Silica Optical Fiber, Journal of the American Ceramic Society, 1988, vol. 71, no. 3, p. 177183.

[3] G.M. Bubel, M.J. Matthewson: Optical fiber reliability implications of uncertainty in the fatigue crack growth model, Optical Engineering, 1991, vol. 30, no. 6, p. 737745.

[4] V.V. Rondinella, M.J. Matthewson: Effect of Loading Mode and Coating on Dynamic Fatigue of Optical Fiber in TwoPoint Bending, Journal of the American Ceramic Society, 1993, vol. 76, no. 1, p. 139-144.

[5] D.L. Brownlow, D.J. DiGiovanni, D. Inniss: Fatigue resistant optical fiber, United States Patent, US005212757A, 1993.

[6] L. Han, X.S. Wu, S.R. Schmid, P. Shah, B.J. Overton: Characterization of Tensile Properties of Optical Fibers Coated with a New Generation Coating System and the Comparison of Fatigue Behavior by Tensile Test and Two Point Bending Technique, Proceedings of the 59th IWCS/ IICIT, p. 242-249.

[7] S.L. Semjonov, G. Glaesemann, D.A. Clark, M.M. Bubnov: Fatigue behavior of silica fibers with different defects, Proc. SPIE 4215, Optical Fiber and Fiber Component Mechanical Reliability and Testing, vol. 4215, p. 28-35.

[8] R. Drobina, A. Włochowicz, M.S. Machnio, E. Drobina, S. Lewandowski: Fatigue Curves Elaborated for Selected Worsted Wool Yarns, Fibers \& Textiles, 2007, vol. 15, no. 5-6, p. 64-65.

[9] J.F. Mandell: Fatigue Behaviour of Short Fibre Composite Materials, Fatigue of Composite Materials, K.L. Reifsnider, Editor, 1990, p. 232-337.

[10] Y.J Tong, D.H. Isaac: Impact and fatigue behaviour of hemp fibre composites, Composites Science and Technology, 2007, vol. 67, no. 15-16, p. 3300-3307. 